\title{
Effect of nitrogen and water deficit type on the yield gap between the potential and attainable wheat yield
}

\author{
Jiangang Liu', Guangyao Wang², Thorp Kelly ${ }^{3}$, Yaoyao Zhang¹, Meng Yang1, and Qingquan Chu ${ }^{1 *}$
}

\begin{abstract}
Water deficit and $\mathrm{N}$ fertilizer are the two primary limiting factors for wheat yield in the North China plain, the most important winter wheat (Triticum aestivum L.) production area in China. Analyzing the yield gap between the potential yield and the attainable yield can quantify the potential for increasing wheat production and exploring the limiting factors to yield gap in the high-yielding farming region of North China Plain. The Decision Support System for Agrotechnology Transfer (DSSAT) model was used to identify methods to increase the grain yield and decrease the gap. In order to explore the impact of $\mathrm{N}$ and cultivars on wheat yield in the different drought types, the climate conditions during 1981 to 2011 growing seasons was categorized into low, moderate, and severe water deficit classes according to the anomaly percentage of the water deficit rate during the entire wheat growing season. There are differences $(\mathrm{P}<0.0001)$ in the variations of the potential yields among three cultivars over $30 \mathrm{yr}$. For all three water deficit types, the more recent cultivars Jimai22 and Shijiazhuang8 had higher yields compared to the older 'Jinan17'. As the $\mathrm{N}$ fertilizer rate increased, the yield gap decreased more substantially during the low water deficit years because of the significant increase in attainable yield. Overall, the yield gaps were smaller with less water stress. Replacement of cultivars and appropriate $\mathrm{N}$ fertilizer application based on the forecasted drought types can narrow the yield gap effectively.
\end{abstract}

Key words: DSSAT, household farm, N availability, potential yield, Triticum aestivum, yield gap.

\section{INTRODUCTION}

The North China Plain is the primary high-yield wheat production area, accounting for over $60 \%$ of the total wheat (Triticum aestivum L.) production in China (Zhao, 2010). The highest recorded wheat yields exceed $10 \mathrm{Mg}$ $\mathrm{ha}^{-1}$ in the North China Plain (Wang et al., 2009; Zhao et al., 2011; Li et al., 2014). The highest recorded yield is usually attained with high water and fertilizer input, good soil conditions, and advanced cultivation and management techniques (Cui et al., 2005; Zhang et al., 2013). Historically, the increase in wheat grain yield during the past $20 \mathrm{yr}$ was primarily due to a substantial increase in irrigation and $\mathrm{N}$ application (Zhang et al., 2013). However, water and $\mathrm{N}$ use efficiency is generally low in the region because of drought stress caused by low

${ }^{1}$ China Agricultural University, College of Agronomy and Biotechnology, Beijing, 100193, China. *Corresponding author (cauchu@cau.edu.cn).

${ }^{2}$ University of California, Desert Research \& Extension Center, 1004 East Holton Road, Holtville, CA 92250, USA.

${ }^{3}$ United States Department of Agriculture (USDA), Arid-Land Agricultural Research Center, 21881 North Cardon Lane, Maricopa, AZ 85138, USA.

Received: 12 December 2014.

Accepted: 10 May 2015.

doi:10.4067/S0718-58392015000500011 amounts of irrigation water and inappropriate irrigation timing as well as over-application of $\mathrm{N}$ fertilizer (Liu et al., 2013). Improved management practices are necessary to allow farmers to increase their water and $\mathrm{N}$ use efficiency and reduce pollution. To ensure food security, research pertaining to high crop yields and high resource efficiency has been performed recently. National programs, such as the Chinese National Basic Research Program for high yield cultivation and the efficient resource utilization of major crops (Program "Liang Feng"), have been established to study high-yield grain production.

Recently, yield potential and yield gap analysis have been used to identify yield-limiting factors and help farmers make decisions about water and $\mathrm{N}$ applications (Abeledo et al., 2008; Anderson, 2010; Alijani et al., 2012; Mueller et al., 2012). In our study, the potential yield is defined as the yield attained when a cultivar is grown under optimal water and nutrient conditions and pests and diseases are effectively controlled, whereas the attainable yield is defined as the yields obtained at research stations with the recommended fertilization, irrigation, and pest control practices. The difference between the potential yield and the attainable yield is the crop yield gap (Lobell et al., 2009).

Although the potential and attainable yields for a given site can be estimated using conventional field experiments, yield information under different growing 
conditions is necessary to perform yield gap analysis. Because measuring the crop yield of different cultivars under different climate scenarios is impractical using conventional field experiments, crop growth models can be used to estimate the potential yield and attainable yield by manipulating the input variables, such as soil, climate, water, and $\mathrm{N}$ conditions (Ghaffari et al., 2001; Rinaldi, 2004; Kalra et al., 2007; Lobell et al., 2009; Basso et al., 2012).

The Decision Support System for Agrotechnology Transfer (DSSAT) model has been used to assess the yield response to climate conditions in different environments and countries and also in the North China Plain (Rinaldi, 2004; Ju et al., 2005a; Yang et al., 2010). This crop model simulates growth and yield as a function of the climate, soil, crop cultivar, and management practices. DSSAT has been widely used to analyze yield gap trends under climate change and the impact of $\mathrm{N}$ on the crop yield gap during recent years (Rinaldi, 2004; Lobell and Monasterio, 2007; Timsina et al., 2008).

Under both rain-fed and irrigated conditions, water and $\mathrm{N}$ are the main limiting factors affecting cereal yield (Cossani et al., 2010; Torabi et al., 2011). However, reports regarding the effects of different agronomic factors, such as cultivars, drought stress, and $\mathrm{N}$ fertilizer rates under different climate conditions are limited (Anderson, 2010). More recent wheat cultivars can also narrow the yield gap under changing climate conditions (Liu et al., 2010). Increasing the $\mathrm{N}$ availability reduced the yield gap in wheat, but the effects of $\mathrm{N}$ fertilizer on the yield gaps depends on water stress (Abeledo et al., 2008). When drought stress is not severe, the response of wheat grain yield to $\mathrm{N}$ fertilization increased. However, the effects of $\mathrm{N}$ on wheat yield are limited when drought stress is severe (Chai et al., 2011).

The objective of this study was to analyze the gap between potential yield and attainable yield of three winter wheat cultivars under different drought types.

\section{MATERIALS AND METHODS}

The field experiments for DSSAT model parameterization, calibration, and validation were conducted at China Agricultural University's Wuqiao Research Station, Hebei Province in China (37 $29^{\prime}-37^{\circ} 47^{\prime} \mathrm{N}, 116^{\circ} 19^{\prime}-116^{\circ} 24^{\prime} \mathrm{E}$; $15 \mathrm{~m}$ a.s.1.) The conditions at the site are representative of the North China Plain. The soil is a loamy fluvoaquic soil type, a common soil type in the North China Plain (Wang et al., 2007). The typical crop rotation in the region is winter wheat-summer corn (Zea mays L.) The annual rainfall fluctuated between 400 and $700 \mathrm{~mm}$, with more rainfall during the summer months (Figure 1). Because rainfall cannot provide sufficient water for the wheat during the growing season, wheat production relies heavily on irrigation. However, the amount of irrigation during the majority of the growing season is not sufficient
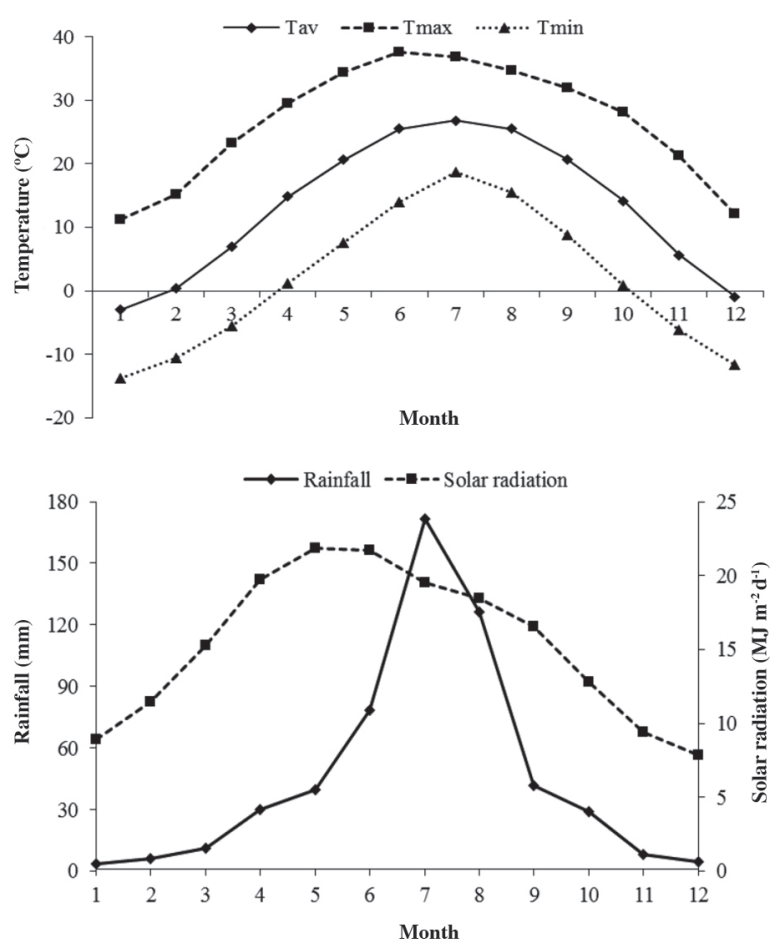

Figure 1. The long-term means of the maximum and minimum temperatures, rainfall and solar radiation at Wuqiao, Hebei, China.

to prevent wheat crop drought stress ( $\mathrm{Lu}$ and Fan, 2013; Liu et al., 2013).

Field experiments were conducted using 'Jimai22' and five $\mathrm{N}$ levels $\left(0,60,120,180\right.$, and $\left.240 \mathrm{~kg} \mathrm{ha}^{-1}\right)$ at Wuqiao Research Station during the 2010-2011 and 2011-2012 growing seasons. During the 2010-2011 growing season, two irrigation levels (150 and $225 \mathrm{~mm}$ ) were also included in the study (Table 1). The experiment was a complete

Table 1. Dates and application amounts of $\mathbf{N}$ fertilizers and irrigation for wheat cultivars for the $N$ experiments at the Wuqiao Research Station.

\begin{tabular}{|c|c|c|c|c|}
\hline Cultivar & Planting date & Nitrogen $^{ \pm}$ & Irrigation & Harvest date \\
\hline & & $\mathrm{kg} \mathrm{ha}^{-1}$ & $\mathrm{~mm} \mathrm{ha}^{-1}$ & \\
\hline Shijiazhuang8 ${ }^{1}$ & 13 Oct 2002 & $250^{\mathrm{g}}$ & $75^{\mathrm{a}}, 225^{\mathrm{b}}, 375^{\mathrm{c}}$ & 12 June 2003 \\
\hline $\operatorname{Jinan} 17^{2}$ & 13 Oct 2002 & $157^{\mathrm{h}}, 226^{\mathrm{h}}$ & $225^{\mathrm{b}}$ & 10 June 2003 \\
\hline $\operatorname{Jinan} 17^{2}$ & 13 Oct 2002 & $0,157^{\mathrm{g}}, 226^{\mathrm{g}}$ & $225^{\mathrm{b}}$ & 10 June 2003 \\
\hline Shijiazhuang $8^{2}$ & 19 Oct 2003 & $157^{\mathrm{g}}, 226^{\mathrm{g}}, 295^{\mathrm{g}}$ & $225^{\mathrm{b}}$ & 10 June 2004 \\
\hline Shijiazhuang8 ${ }^{2}$ & 19 Oct 2003 & $157^{\mathrm{h}}, 226^{\mathrm{h}}, 295^{\mathrm{h}}$ & $225^{\mathrm{b}}$ & 10 June 2004 \\
\hline Jinan $17^{3}$ & 13 Oct 2004 & $157^{\mathrm{g}}, 226^{\mathrm{g}}, 295^{\mathrm{g}}$ & $150 \mathrm{~d}$ & 12 June 2005 \\
\hline Jinan $17^{3}$ & 13 Oct 2004 & $157^{\mathrm{g}}, 226^{\mathrm{g}}, 295^{\mathrm{g}}$ & $225^{\mathrm{b}}$ & 12 June 2005 \\
\hline Shijiazhuang $8^{4}$ & 13 Oct 2004 & $125^{\mathrm{g}}$ & $105^{\mathrm{e}}$ & 10 June 2005 \\
\hline Shijiazhuang8 ${ }^{4}$ & 13 Oct 2005 & $105^{\mathrm{g}}$ & $116^{\mathrm{e}}$ & 10 June 2006 \\
\hline Jimai $22^{5}$ & 14 Oct 2008 & $180^{\mathrm{g}}$ & $225^{\mathrm{b}}$ & 12 June 2009 \\
\hline Jimai $22^{6}$ & 16 Oct 2010 & $192^{\mathrm{g}}, 270^{\mathrm{g}}$ & $150 \mathrm{e}, 225^{\mathrm{f}}$ & 15 June 2011 \\
\hline Jimai $22^{7}$ & 14 Oct 2010 & $180^{\mathrm{g}}$ & $15 \mathrm{e}, 225^{\mathrm{f}}$ & 12 June 2011 \\
\hline Jimai $22^{7}$ & 14 Oct 2010 & $0,60^{\mathrm{g}}, 120^{\mathrm{g}}, 180^{\mathrm{g}}, 240^{\mathrm{g}}$ & $225^{\mathrm{f}}$ & 12 June 2011 \\
\hline Jimai $22^{7}$ & 14 Oct 2011 & $0,60^{\mathrm{g}}, 120^{\mathrm{g}}, 180^{\mathrm{g}}, 240^{\mathrm{g}}$ & $225^{\mathrm{f}}$ & 12 June 2012 \\
\hline
\end{tabular}

${ }^{ \pm}$Values divided by comma mean different levels.

arrigation at pre-planting; 'Irrigation at pre-planting, jointing and anthesis stage; 'Irrigation at pre-planting, jointing, anthesis and grain filling stage; ${ }^{\mathrm{d}}$ Irrigation at jointing and anthesis stage; ${ }^{\mathrm{e}}$ Irrigation at pre-planting and jointing

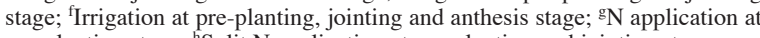
pre-planting stage; hSplit $\mathrm{N}$ application at pre-planting and jointing stages.

${ }^{1}$ Wu et al., 2008; ${ }^{2}$ Zhang et al., 2007; ${ }^{3}$ Wang et al., 2007; ${ }^{4}$ Liu et al., 2008;

${ }^{5}$ Wang et al., 2010b; ${ }^{6}$ Zang et al., 2012; ${ }^{7}$ Liu et al., 2013. 
randomized block design with four replicates. The detailed management practices, wheat phenology, leaf area index (LAI), leaf chlorophyll content, grain filling rate, and soil nutrient status were recorded during the growing season. At harvest, wheat yields and yield components were determined. In addition to the experiments, data on the wheat phenology, yields and yield components, and management practices from previous $\mathrm{N}$ and irrigation experiments at Wuqiao Research Station were obtained from the station records and publications. The data used to calibrate the parameters of 'Jimai22', 'Shijiazhuang8', and 'Jinan 17' were obtained from an experiment with five $\mathrm{N}$ levels during the 2010-2011 growing season, an experiment with six $\mathrm{N}$ levels during the 2003-2004 growing season, and an experiment with five $\mathrm{N}$ levels during the 2002-2003 growing season, respectively (Table 1). 'Jinan17', 'Shijiazhuang8', and 'Jimai22' were the dominant wheat cultivars in the region during 1995-2000, 2001-2005, and 2006-2010, respectively. The other required input data for the DSSAT include the daily weather data, soil surface and profile information, and detailed crop management information. The daily weather data were collected at the local weather bureau.

After parameterization of the DSSAT models, the experiments using 'Jinan17' with six water-N treatments during 2004-2005, 'Shijiazhuang8' with three irrigation treatments during 2002-2003 and two different water-N treatments during 2004-2006, and 'Jimai22' with two irrigation levels during 2010-2011 and five $\mathrm{N}$ treatments during 2011-2012 were used to validate the model (Table 1). The "trial and error" method was used to calibrate the genetic coefficients of the winter wheat for the DSSAT model (Wen and Chen, 2011). After validation, the DSSAT models were used to simulate the wheat growth and yield under different $\mathrm{N}$ fertilizer applications at the Wuqiao Research Station from the 1981 to 2011 growing seasons.

After DSSAT model validation, the potential yield was estimated using the DSSAT model assuming that either $\mathrm{N}$ or water was not limited during each of 1981 to 2011 growing seasons. The attainable yields were obtained using the recommended agricultural practices at the Wuqiao Research Station. The soil properties at the Wuqiao Research Station were used in the simulations. The simulations were performed with detailed climate data for Wuqiao from 1981 to 2011, which were obtained from the Wuqiao Meteorological Database. The yield gaps were the difference between the potential yield and attainable yield. The evaluations were performed with October 14 as the standard sowing date using 'Jimai22', 'Shijiazhuang8', and 'Jinan17'.

The climate during the 1981 to 2011 growing seasons was divided into three rainfall types according to the anomaly percentage of the water deficit rate during the entire wheat growing season as follows: low water deficit years, moderate water deficit years, and severe water deficit years. The computational formula of the anomaly percentage of the water deficit rate is as follows:

$$
\alpha_{i}=\frac{R_{i}-\bar{R}}{\bar{R}} \times 100 \%
$$

where $\alpha_{i}$ is the anomaly percentage of the water deficit rate in the year $i, R_{i}$ is the water deficit rate in the year $i$, and $\bar{R}$ is the average of the water deficit rate from 1981 to 2011.

The water deficit rate $\left(R_{i}\right)$ is defined as follows:

$$
R_{i}=\frac{E T_{m}-E T_{a}}{E T_{m}} \times 100 \%
$$

where $E T_{m}$ is the potential wheat crop evapotranspiration simulated by the DSSAT model during the growing season, which is the amount of water required for wheat production without any drought stress, and $E T_{a}$ is the actual evapotranspiration by the wheat crop simulated by the model during the growing season (Sun and Feng, 2005). Severe water deficit type was defined as $\alpha_{i} \geq$ $20 \%$, which means worst water supply conditions in the growing seasons of winter wheat. Moderate water deficit type was defined as $-20 \%<\alpha_{i}<20 \%$, while light water deficit type was defined as $\alpha_{i} \leq-20 \%$ (Li et al., 2009).

The normalized root mean squared error (NRMSE) was used to measure the difference between the simulated and observed yields for model calibration (Timsina et al., 2008):

$$
\text { NRMSE }=\sqrt{\frac{\sum_{i=1}^{n}\left(S_{i}-R_{i}\right)^{2}}{n}} \times \frac{100}{\overline{\mathrm{R}}}
$$

where $\mathrm{Si}$ and $R_{i}$ are the simulated and observed yield, respectively, $\bar{R}$ is the mean observed yields, and $n$ is the numbers of samples. The smaller the NRMSE is, the better the DSSAT model simulates the crop yield. A NRMSE value $<20 \%$ indicates that the DSSAT model accurately predicted the crop yield, whereas a NRMSE value $>30 \%$ indicates that the DSSAT model did not accurately predict the crop yield (Wen and Chen, 2011; Liu et al., 2013).

Cumulative distribution functions were used to evaluate the variations of potential yield and attainable yield under different $\mathrm{N}$ fertilizer rates at Wuqiao for 30 yr (Xue and Titterington, 2011). For evaluating the yield gap of the three cultivars, ten $\mathrm{N}$ fertilizer levels were used to simulate the attainable yield for each of the $30 \mathrm{yr}$. The difference of the average potential yield and average attainable yield were calculated as the crop yield gap. The yield gaps under different water-deficit types were then analyzed to determine the yield gap response to the cultivars and $\mathrm{N}$ fertilizer rates.

\section{RESULTS AND DISCUSSION}

\section{Model calibration and validation}

After the DSSAT model was parameterized and calibrated, validation of the model using data from eight field experiments with 'Jimai22', 'Shijiazhuang8', and 'Jinan 17' showed that the model accurately predicted the observed yield (Figure 2). The NRMSE between the 


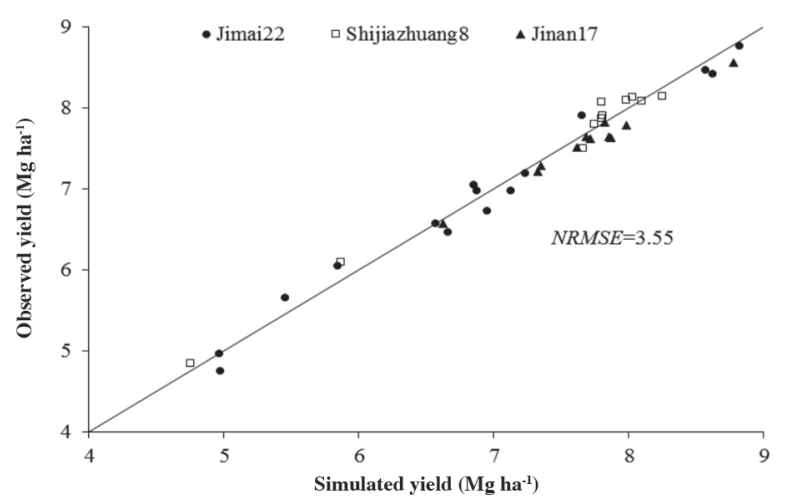

NRMSE: Normalized root mean squared error.

Figure 2. The simulated and observed grain yields for the three wheat 'Jimai22', 'Shijiazhuang8', and 'Jinan17' for experiments at Wuqiao, Hebei, China. The straight line represents the 1:1 relationship.

simulated yields and observed yields was 3.5, indicating that the simulated wheat grain yields were similar to the observed yields and that the DSSAT model can be used to simulate the winter wheat yield of these cultivars in the region.

Crop models have been widely used to simulate and compare crop yields under conditions that are difficult to study in the field directly. Among these models, the DSSAT model is commonly used in China with proven performance under many conditions (Sun et al., 2005b; Wen and Chen, 2011). The amount of the potential yield simulated by the DSSAT model ranged from 6.9 to 12.8 $\mathrm{Mg} \mathrm{ha}^{-1}$ for the three cultivars used in the present study, which is larger than yields obtained using the Agricultural Production Systems Simulator (APSIM) and CropSyst models for this region (Li et al., 2009; Lu and Fan, 2013). The reason for the difference is that the initial conditions set for the simulation in our study were refer to the inputs and the management practices for achieving high yield in experimental station.

\section{Water conditions for wheat production}

The potential evapotranspiration at the Wuqiao Research Station ranged from 500.9 to $566.4 \mathrm{~mm}$, whereas the actual evapotranspiration ranged from 236.9 to $403.8 \mathrm{~mm}$ from 1981 to 2011. The average water deficit rate from 1981 to 2011 was $42.2 \%$, indicating that the wheat yield is significantly decreased by severe water deficit conditions (Li et al., 2009). The moderate water deficit years are the dominant rainfall year type, which accounted for $53 \%$ of the years during the $30 \mathrm{yr}$, whereas the severe water deficit years accounted for $27 \%$ and the low water deficit years accounted for only $20 \%$ (Table 1). This indicates that water deficit is the major limiting factor for wheat production in the region.

The gap between the potential yield and attainable yield are commonly assessed and studied under different management practices and climate conditions (Ju et al., 2005; Liu et al., 2010; Lu and Fan, 2013; Carberry et al., 2013). The results of this study complement a previous study for the same region (Liu et al., 2013). The previous study analyzed the yield gap between the maximum yield obtained with the optimal $\mathrm{N}$ and farmer yield, and highlighted that the effect of excess $\mathrm{N}$ on the field. In this study, we categorized the climates in 1981 to 2011 into three water deficit types. The wheat cultivars responded differently to the $\mathrm{N}$ fertilizer rates under the different water deficit types. Categorizing the water deficit types makes it easier to study the cultivar response to the $\mathrm{N}$ fertilizer because the impact of $\mathrm{N}$ on the wheat yield can be separated by the different rainfall year types, which can help farmers apply the appropriate amount of $\mathrm{N}$ during different rainfall years and predict future yields according to the climate (Abeledo et al., 2008; Li et al., 2009; Basso et al., 2013). The impact of $\mathrm{N}$ on the crop yield gap varied depending on the rainfall conditions during the growing season (Abeledo et al., 2008; Basso et al., 2012).

\section{Assessing the gap between the potential yield and attainable yield}

The cumulative probability distribution of the potential yield showed significant differences among the cultivars (Figure 3). The potential yield from 1981 to 2011 simulated by the DSSAT model ranged from 7.3 to $12.9,7.0$ to 11.6 , and 6.9 to $10.6 \mathrm{Mg} \mathrm{ha}^{-1}$ for 'Jimai22', 'Shijiazhuang8', and 'Jinan17', respectively (Table 1). The reason for the difference in the potential yield among the three cultivars is that the harvest index increased for the newest cultivars (Wang et al., 2010a; Liu et al., 2010). The potential yield of the three cultivars was higher than the highest recorded yield in Wuqiao, indicating that increased wheat yield is possible. The coefficient of variation of the highest recorded yield was $6.48 \%, 3.03 \%$, and $2.50 \%$ for 'Jimai22', 'Shijiazhang', and 'Jinan17', respectively, indicating that 'Jinan17' was more stable during the highest recorded yield.

When no $\mathrm{N}$ fertilizer was applied during sowing, the maximum and mean attainable yields averaged over the three cultivars were 2.8 and $2.1 \mathrm{Mg} \mathrm{ha}^{-1}$, respectively (Figure 4). Applying $\mathrm{N}$ fertilizer at sowing significantly

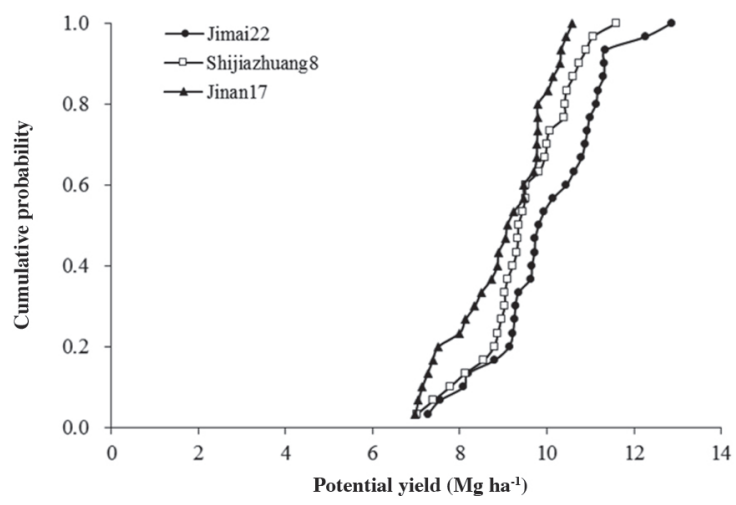

Figure 3. The cumulative frequency distribution of the simulated potential yield for the three wheat cultivars simulated from 1981 to 2011 at Wuqiao, Hebei, China. 

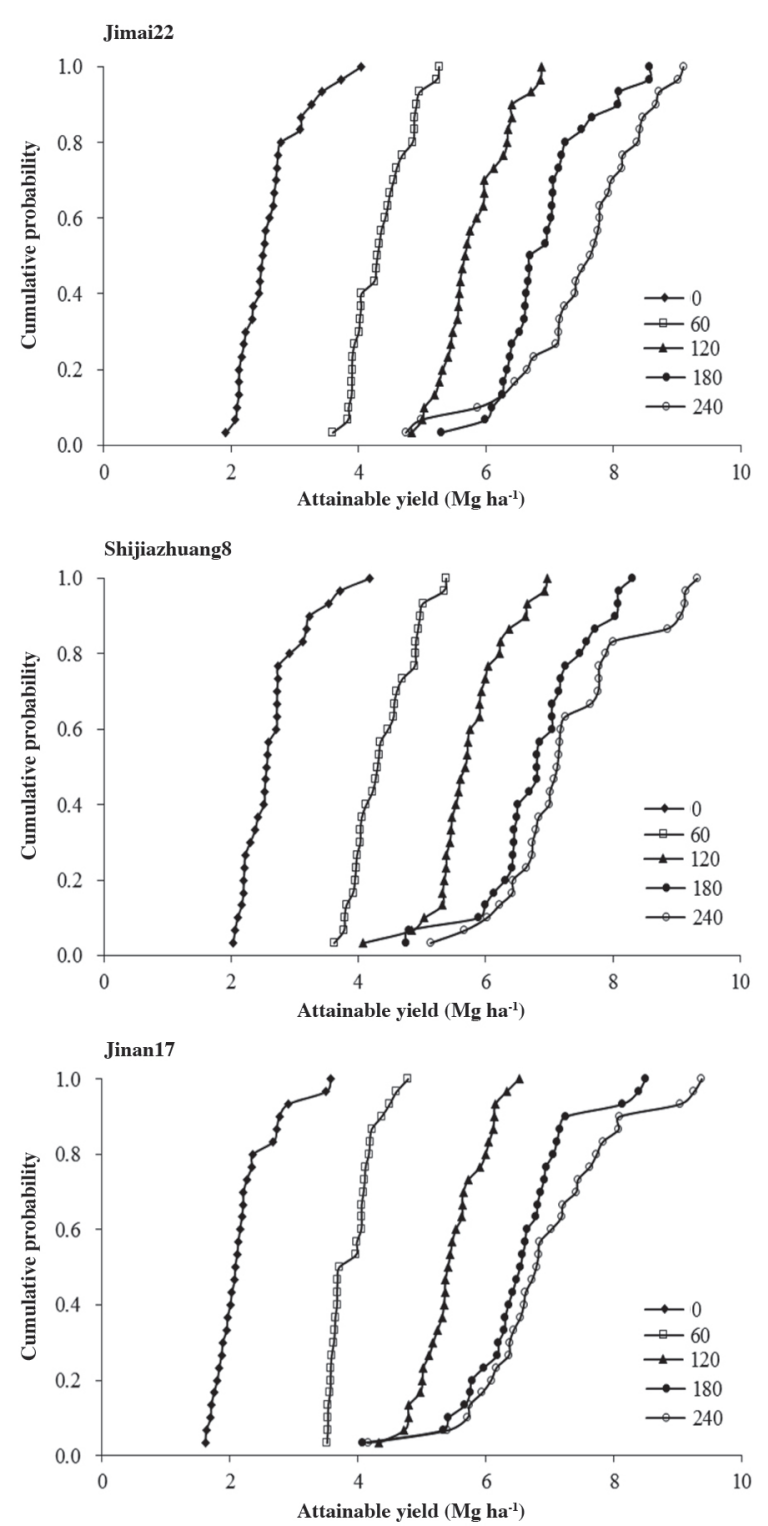

Figure 4. The cumulative frequency distribution simulated attainable yield for the three cultivars growing under $\mathbf{N}$ availabilities at sowing of $0,60,120,180$, and $240 \mathrm{~kg} \mathrm{ha}^{-1}$ using a long-term simulation ( $30 \mathrm{yr}$, 1981-2011) for Wuqiao (North China Plain).

increased the attainable yield. The differences in attainable yield among three cultivars were small when no $\mathrm{N}$ fertilizer was applied at sowing. When $240 \mathrm{~kg} \mathrm{ha}^{-1}$ of $\mathrm{N}$ fertilizer was applied at sowing, the mean attainable yields were 6.7, 6.4, and 6.3 $\mathrm{Mg} \mathrm{ha}^{-1}$ for 'Jimai22', 'Shijiazhuang8', and 'Jinan 17', respectively, indicating that the more recent cultivars grew better with high $\mathrm{N}$ fertilization. As the rate of $\mathrm{N}$ fertilizer application increased, the variations among years in the attainable yield also increased significantly. This is because the limited $\mathrm{N}$ supply was a more dominant factor than climate when $\mathrm{N}$ fertilizer rate was low. When $\mathrm{N}$ fertilizer rate was high, significant variations in attainable yields were caused by the climate variations among the different years. The recommended $\mathrm{N}$ fertilizer rate under severe water deficit years can be decreased to $180 \mathrm{~kg}$ $\mathrm{ha}^{-1}$ without significant decrease in the attainable yield, while the existing local recommended $\mathrm{N}$ fertilizer rate is $210 \mathrm{~kg} \mathrm{ha}^{-1}$ for every year.

The yield gap of three cultivars decreased with increasing $\mathrm{N}$ fertilizer application. When no $\mathrm{N}$ fertilizer was applied at sowing, the mean yield gaps were 7.4, 6.7 and 6.7 $\mathrm{Mg} \mathrm{ha}^{-1}$ for 'Jimai22', 'Shijiazhuang8' and 'Jinan13', respectively. Applying $\mathrm{N}$ fertilizer at sowing decreased the yield gap significantly. When $240 \mathrm{~kg} \mathrm{ha}^{-1}$ of $\mathrm{N}$ fertilizer was applied at sowing, the mean yield gap was 2.4, 2.0, and 1.9 $\mathrm{Mg} \mathrm{ha}^{-1}$ for 'Jimai22', 'Shijiazhuang8', and 'Jinan17', respectively. The yield gap of 'Jimai22' was higher than the yield gap of the other cultivars, which is caused by the higher potential yield of 'Jimai22'.

The attainable yield at Wuqiao was higher than the yield attained in Europe (Abeledo et al., 2008; Brisson et al., 2010). The high attainable yield in the region was caused by high water and $\mathrm{N}$ input, high soil fertility, and climate suitable for winter wheat production. Because the wheat yields in the majority of fields are lower than the yields attained with under the experimental conditions, measures to narrow the gap must be studied. Additionally, narrowing the gap between the potential yield and attainable yield is more difficult. Although the recorded experimental wheat yield was close to the potential yield on small scales, replicating these yields on a large scale is unlikely. The newer cultivars obtained higher yield than the older cultivars, which was identical to the conclusion that changing to new crop varieties in the North China Plain can compensate for the negative impact of climate change (Liu et al., 2010). The reason for the higher yield is the increase of the harvest index (Liu et al., 2010). The response of the wheat yield to irrigation and fertilization was dependent on the cultivar. However, the maximum attainable yield is not significantly improved, the average maximum attainable was about $10.1 \mathrm{Mg} \mathrm{ha}^{-1}$ (Liu et al, 2013), and therefore narrowing the yield gap is a reasonable method of increasing the regional yield and achieving sustainable agriculture.

\section{Water and $\mathrm{N}$ as determinants of yield gap}

Averaged over $30 \mathrm{yr}$, the wheat attainable yield increased as the $\mathrm{N}$ supply increased. 'Jimai22' and 'Shijiazhang8' had higher yields than 'Jinan17', indicating that the newer cultivars had higher yields under low and high $\mathrm{N}$ conditions (Figure 5). For all three water deficit types, both 'Jimai22' and 'Shijiazhuang8' had higher yields compared to 'Jinan17'. However, the differences varied significantly under different drought types and $\mathrm{N}$ fertilizer rates. During the low water deficit years with less water stress, differences in the grain yield among cultivars were significant when the $\mathrm{N}$ fertilizer rates were low but became smaller when the $\mathrm{N}$ fertilizer rate was higher than $210 \mathrm{~kg} \mathrm{ha}^{-1}$. This indicates that 'Jinan 17 ' produced a grain yield close to the more recent cultivars with adequate N supply and less drought. During 

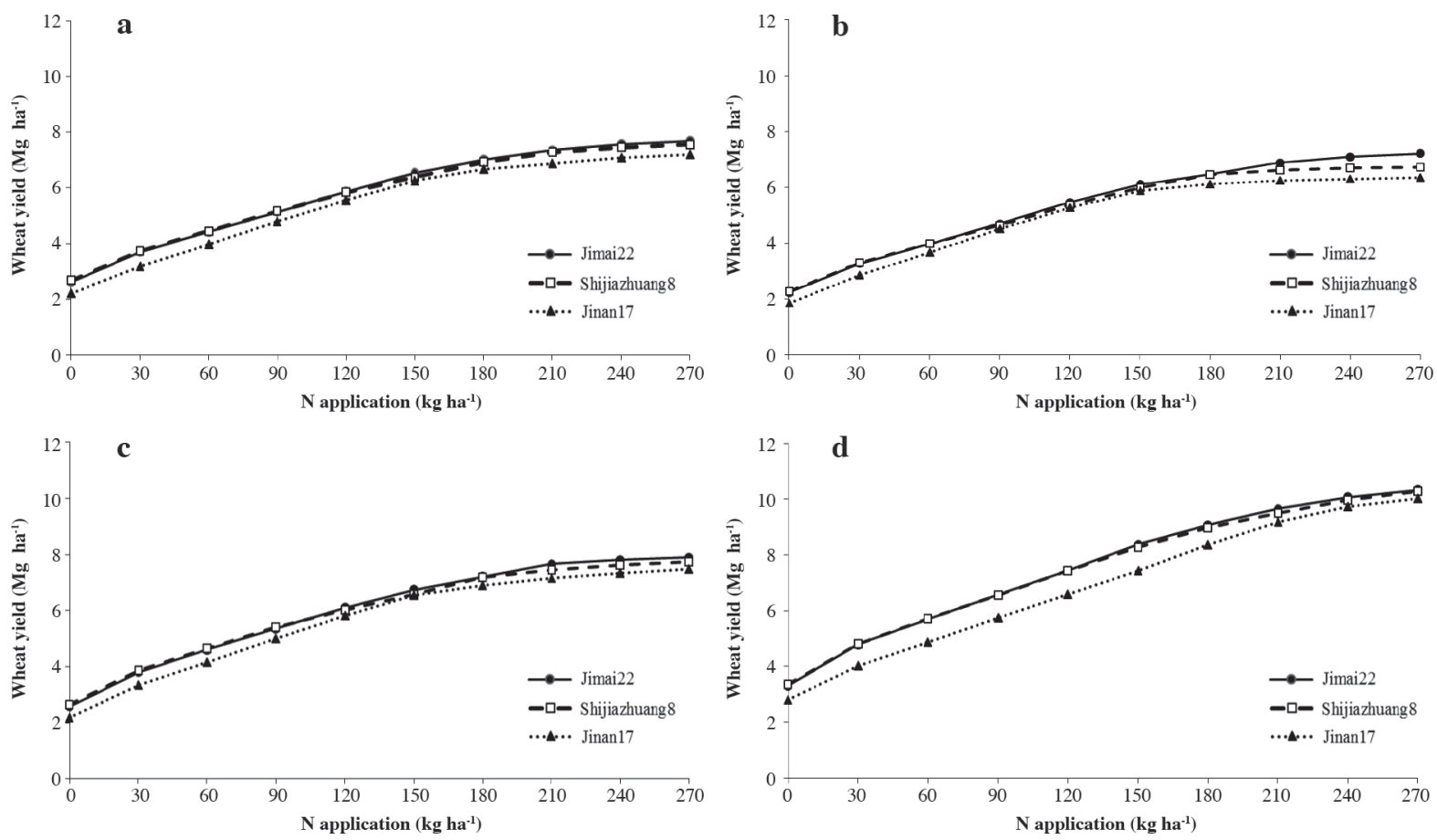

Figure 5. The simulated attainable yield for the three cultivars growing under $\mathrm{N}$ availabilities at sowing of $0,30,60,90,120,150,180,210,240$ and $270 \mathrm{~kg} \mathrm{ha}^{-1}$ using a long-term simulation (30 yr, 1981-2011) for Wuqiao (North China Plain): mean value (a), under severe water-deficit yr (b), under moderate water-deficit years (c), under light water-deficit years (d).

the moderate water deficit years, differences among the cultivars were smaller compared to the low water deficit years. During the severe water deficit years, the attainable yield of 'Jimai22' was higher than the other two cultivars, which indicated that the newest cultivar performed better than the old cultivars under both low and high $\mathrm{N}$ levels during the severe water deficit years. The attainable yield of the three cultivars during the severe water-deficit years decreased by more than $28 \%$ over the attainable yield during the low water-deficit years when the $\mathrm{N}$ fertilizer rate was $0 \mathrm{~kg} \mathrm{ha}^{-1}$. The differences among the cultivars were larger when the $\mathrm{N}$ fertilizer rate was higher than 240 $\mathrm{kg} \mathrm{ha}^{-1}$. Overall, the wheat yield decreased as the water deficit severity increased, indicating that water deficit was a significant limiting factor to the attainable yield for the three cultivars.

As the $\mathrm{N}$ fertilizer rates increased, the yield gap of all three cultivars decreased significantly, indicating that the increased application of $\mathrm{N}$ fertilizer can narrow the yield gap between the potential yield and attainable yield (Figure 6). During the low water deficit years, the yield gap between the potential yield and attainable yield under different $\mathrm{N}$ levels of the three cultivars was smaller compared to the moderate and severe water deficit years. As $\mathrm{N}$ the fertilizer rate increased, the yield gap of 'Jinan17' decreased more rapidly than 'Jimai22' and 'Shijiazhuang8', indicating that 'Jinan17' was more responsive to $\mathrm{N}$ fertilizer application during the low water deficit years. During both the moderate and severe water deficit years, 'Jimai22' had a higher yield gap than 'Shijiazhuang8' and 'Jinan17'. When the $\mathrm{N}$ fertilizer rate was $270 \mathrm{~kg} \mathrm{hm}^{-2}$, the yield gap can be decreased up to $82.8 \%$ than the yield gap without $\mathrm{N}$ application under light water deficit years, while it was $65.9 \%$ under severe water deficit years. Overall, the yield gaps were smaller with less water stress. As the $\mathrm{N}$ fertilizer rate increased, the yield gap was reduced more significantly during the low water deficit years because of a significant increase in the attainable yield compared to the moderate and severe water deficit years.

The actual wheat yields achieved by farmers and researchers in the North China Plain are generally high, although there is significant spatial variability (Liu et al., 2013). However, because of the over-application of $\mathrm{N}$ fertilizer to wheat and other crops, it is necessary to adopt better management practices to increase water and $\mathrm{N}$ use efficiency and reduce pollution in the region (Liu et al., 2013). Many studies have focused on the impact of $\mathrm{N}$ and water on the crop yield (Abeledo et al., 2008; Torabi et al., 2011; Basso et al., 2013; Carberry et al., 2013). The N fertilizer rate recommendations by the local agricultural extension personnel have been used for many years and do not change during the different water deficit years. However, the climate can vary significantly from year to year because of the temperate monsoon climate as shown in our study. The optimal $\mathrm{N}$ amount for a region with the 

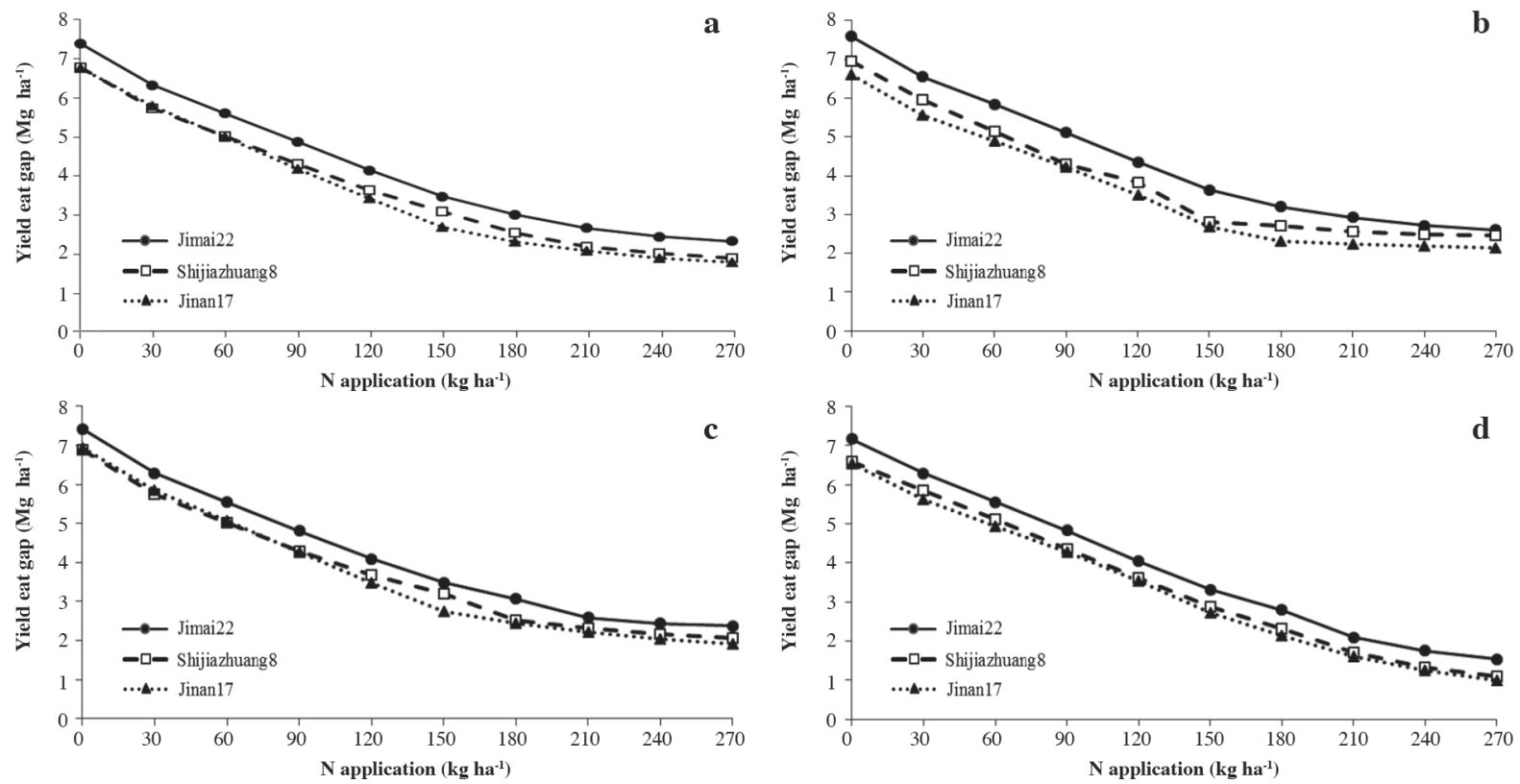

Figure 6. Yield gap between the potential yield and attainable yield of the three wheat cultivars under $N$ fertilizer rates of $0,30,60,90,120,150$, $180,210,240$, and $270 \mathrm{~kg} \mathrm{ha}^{-1}$ at sowing simulated from 1981 to 2011 at Wuqiao, Hebei, China: average yield gap for $30 \mathrm{yr}$ in Wuqiao (a), yield gap under severe water-deficit years (b), yield gap under moderate water-deficit years (c), yield gap under light water-deficit years (d).

same agricultural practices is not fixed but varies with the rainfall amount (Basso et al., 2013). This requires different recommended $\mathrm{N}$ fertilizer rates during different years as a method of improving $\mathrm{N}$ and water use efficiency.

\section{CONCLUSIONS}

The DSSAT model is a helpful tool to analyze the yield gap of winter wheat in the North China Plain. The attainable yield and the yield gap varied with the water deficit types and the $\mathrm{N}$ fertilizer rates. The increased application of $\mathrm{N}$ can narrow the yield gap between the potential yield and the attainable yield under all water deficit types. However, the yield gap was reduced most significantly during the low water deficit years because of the high attainable yield. Decreasing the amount of $\mathrm{N}$ application to a certain extent has little impact on narrowing the yield gap during the severe water deficit years. The recent cultivars Jinan22 and Shijiazhuang8 are better adapted to high $\mathrm{N}$ availability, but the variations among the years in the attainable yield also increased significantly as the rate of $\mathrm{N}$ fertilizer application increased. An increased yield can be achieved by replacing new cultivars and using different recommended $\mathrm{N}$ fertilizer rates during different water deficit years.

\section{LITERATURE CITED}

Abeledo, L.G., R. Savin, and G.A. Slafer. 2008. Wheat productivity in the Mediterranean Ebro Valley: Analyzing the gap between attainable and potential yield with a simulation model. European Journal of Agronomy 28:541-550.
Alijani, K., M.J. Bahrani, and K.A. Kazemeini. 2012. Shortterm responses of soil and wheat yield to tillage, corn residue management and nitrogen fertilization. Soil and Tillage Research $124: 78-82$

Anderson, W.K. 2010. Closing the gap between actual and potential yield of rainfed wheat. The impacts of environment, management and cultivar. Field Crops Research 116:14-22.

Basso, B., D. Cammarano, C. Fiorentino, and J.T. Ritchie. 2013. Wheat yield response to spatially variable nitrogen fertilizer in Mediterranean environment. European Journal of Agronomy 51:65-70.

Basso, B., C. Fiorentino, D. Cammarano, G. Cafiero, and J. Dardanelli. 2012. Analysis of rainfall distribution on spatial and temporal patterns of wheat yield in Mediterranean environment. European Journal of Agronomy 41:52-65.

Brisson, N., P. Gate, D. Gouache, G. Charmet, F.X. Oury, and F. Huard. 2010. Why are wheat yields stagnating in Europe? A comprehensive data analysis for France. Field Crops Research 119:201-212.

Carberry, P.S., W.L. Liang, S. Twomlow, D.P. Holzworth, J.P. Dimes, T. McClelland, et al. 2013. Scope for improved eco-efficiency varies among diverse cropping systems. Proceedings of the National Academy of Sciences of the United States of America 110:8381-8386.

Cossani, C.M., G.A. Slafer, and R. Savin. 2010. Co-limitation of nitrogen and water, and yield and resource-use efficiencies of wheat and barley. Crop and Pasture Science 61:844-851.

Cui, Z.L., L.W. Shi, J.F. Xu, J.L. Li, F.S. Zhang, and X.P. Chen. 2005. Effects of $\mathrm{N}$ fertilization on winter wheat grain yield and its crude protein content and apparent $\mathrm{N}$ losses. Chinese Journal of Applied Ecology 16:2071-2075 (in Chinese with English abstract).

Chai, Y.J., J.F. Yuan, Y.S. Xiong, L. Huang, S. J. Zhao, C.L. Peng, et al. 2011. Study on differences of nitrogen efficiency and physiologic of different winter wheat varieties. Soils and Fertilizers 1:21-25 (in Chinese with English abstract).

Ghaffari, A., H.F. Cook, and H.C. Lee. 2001. Simulating winter wheat yields under temperate conditions: exploring different management scenarios. European Journal of Agronomy $15: 231-240$ 
Ju, H., W. Xiong, Y.L. Xu, and E.D. Lin. 2005. Impacts of climate change on wheat yield in China. Acta Agronomica Sinica 31:13401343 (in Chinese with English abstract).

Kalra, N., D. Chakraborty, R. Kumar, M. Jolly, and K. Sharma. 2007. An approach to bridging yield gaps, combining response to water and other resource inputs for wheat in northern India, using research trials and farmers' fields data. Agricultural Water Management 93:54-64.

Li, Q.X., C.Y. Wang, D.Y. Ma, Y.X. Xie, W.X. Liu, Y.J. Zhu, et al. 2014. Effects of irrigation and nitrogen application on grain yield, protein content and quality traits of winter wheat in High-yielding area. Journal of Triticeae Crops 34:102-107 (in Chinese with English abstract).

Li, Y., C.Y. Xue, X.G. Yang, J. Wang, Y. Liu, and E.L. Wang. 2009. Reduction of yield risk of winter wheat by appropriate irrigation based on APSIM model. Transactions of the Chinese Society of Agricultural Engineering 25:35-44 (in Chinese with English abstract).

Liu, J.G., Q.Q. Chu, G.Y. Wang, F. Chen, and Y.Y. Zhang. 2013. Simulating yield gap of winter wheat in response to nitrogen management in North China Plain based on DSSAT model. Transactions of the Chinese Society of Agricultural Engineering 29:124-129 (in Chinese with English abstract).

Liu, M., H.B. Tao, P. Wang, L.H. Lv, and Y.J. Zhang. 2008. Analysis of different cropping systems using optimizing water nitrogen management on yield, water and nitrogen utilization and economic benefits. Journal of China Agricultural University 13:12-18 (in Chinese with English abstract)

Liu, Y., E.L. Wang, X.G. Yang, and J. Wang. 2010. Contributions of climatic and crop varietal changes to crop production in the North China Plain, since 1980s. Global Change Biology 16:2287-2299.

Lobell, D.B., K.G. Cassman, and C.B. Field. 2009. Crop yield gaps: Their importance, magnitudes, and causes. Annual Review of Environment and Resources 34:179-204.

Lobell, D.B., and J.O. Monasterio. 2007. Impacts of day versus night temperatures on spring wheat yields: A comparison of empirical and CERES model predictions in three locations. Agronomy Journal 99:469-477.

Lu, C.H., and L. Fan. 2013. Winter wheat yield potentials and yield gaps in the North China Plain. Field Crops Research 143:98-105.

Mueller, N.D., J.S. Gerber, M. Johnston, D.K. Ray, N. Ramankutty, and J.A. Foley. 2012. Closing yield gaps through nutrient and water management. Nature 490:254-257.

Rinaldi, M. 2004. Water availability at sowing and nitrogen management of durum wheat: a seasonal analysis with the CeresWheat model. Field Crops Research 89:27-37.

Sun, N., and L.P. Feng. 2005. Assessing the climatic risk to crop yield of winter wheat using crop growth models. Transactions of the Chinese Society of Agricultural Engineering 21:106-110 (in Chinese with English abstract).

Sun, F., X. Yang, E.D. Lin, H. Ju, and W. Xiong. 2005. Study on the sensitivity and vulnerability of wheat to climate change in China. Scientia Agricultura Sinica 38:692-696 (in Chinese with English abstract).

Timsina, J., D. Godwin, E. Humphreys, Y. Singh, B. Singh, S.S. Kukal, et al. 2008. Evaluation of options for increasing yield and water productivity of wheat in Punjab, India using the DSSATCSM-CERES-Wheat model. Agricultural Water Management 95:1099-1110.
Torabi, B., A. Soltani, S. Galeshi, and E. Zeinali. 2011. Assessment of yield gap due to nitrogen management in wheat. Australian Journal of Crop Science 5:879-884

Wang, H., F. Chen, Q.H. Shi, S.C. Fan, and Q.Q. Chu. 2010a. Analysis of factors on impacting potential productivity of winter wheat in Huanghuaihai agricultural area over 30 years. Transactions of the Chinese Society of Agricultural Engineering 26:90-95 (in Chinese with English abstract).

Wang, C.Z., L.T. Li, J. Chen, M.Q Liu, and Z.R. Yu. 2009. Status and perspective of crop yield gap. Chinese Journal of Eco-Agriculture 17:1283-1287 (in Chinese with English abstract)

Wang, H.X., Y.Y. Li, T.Z. Ren, and H.C Pang. 2010b. Effects of different irrigation regimes on yield and WUE of winter wheat. Journal of Irrigation and Drainage 29:112-114 (in Chinese with English abstract)

Wang, M., S.Q. Zhang, B.Q. Fang, Q. Zheng, and Y.H. Zhang 2007. Effect of nitrogen applications on grain yield and nitrogen use efficiency of winter wheat in limited water supply. Chinese Agricultural Science Bulletin 23:349-353 (in Chinese with English abstract).

Wen, X.Y., and F. Chen. 2011. Simulation of climatic change impacts on yield potential of typical wheat varieties based on DSSAT model. Transactions of the Chinese Society of Agricultural Engineering 27:1-6 (in Chinese with English abstract).

Wu, Y.C., Y.P. Zhang, S.L. Zhou, and Z.M. Wang. 2008. Yield and characteristics of water and nitrogen utility in winter wheat under different irrigation. Ecology and Environment 17:2082-2085 (in Chinese with English abstract).

Xue, J.H., and D.M. Titterington. 2011. The p-folded cumulative distribution function and the mean absolute deviation from the p-quantile. Statistics \& Probability Letters 81:1179-1182.

Yang, Y.M., Y.H. Yang, J.P. Moiwo, and Y.K. Hu. 2010. Estimation of irrigation requirement for sustainable water resources reallocation in North China. Agricultural Water Management 97:1711-1721.

Zang, H.C., Y.P. Liu, L. Cao, Y.H. Zhang, and Z.M. Wang. 2012. Nitrogen absorption and utilization characteristics of two highyield winter wheat cultivars under limited irrigation and nitrogen supply. Journal of Triticeae Crops 32:503-509.

Zhang, F.S., X.P. Chen, and P. Vitousek. 2013. Chinese agriculture: An experiment for the world. Nature 497:33-35.

Zhang, X., Y.Q. Luo, S.Q. Zhang, Y.C. Wu, M. Wang, and Z.M. Wang. 2007. Effect of different fertilization way on yield and protein content of winter wheat under water-saving cultivation system. Agricultural Research In The Arid Areas 25:45-49 (in Chinese with English abstract).

Zhao, G.C. 2010. Study on Chinese wheat planting regionalization. Journal of Triticeae Crops 30:886-895 (in Chinese with English abstract).

Zhao, G.C., X.H. Chang, Y.S. Yang, M. Feng, S.K. Ma, and G.X. Yang. 2011. Adjustment effect of nitrogen phosphorus potassium operation on grain yield and quality in different variety of wheat. Journal of Triticeae Crops 31:106-112 (in Chinese with English abstract). 